\title{
Heated humidified high-flow nasal cannula therapy in children
}

\author{
F A Hutchings, ${ }^{1}$ T N Hilliard, ${ }^{1}$ P J Davis ${ }^{2}$
}

${ }^{1}$ Department of Paediatric Respiratory Medicine, Bristol Royal Hospital for Children, Bristol, UK

2Department of Paediatric Intensive Care, Bristol Royal Hospital for Children, Bristol, UK

\section{Correspondence to} Dr Frances Hutchings, Department of Paediatric Respiratory Medicine, Bristol Royal Hospital for Children, Upper Maudlin Street, Bristol BS2 8BJ, UK:

fhutchings@doctors.org.uk

Received 2 October 2014 Revised 11 November 2014

Accepted 12 November 2014 Published Online First

1 December 2014

\section{ABSTRACT}

Heated humidified high-flow nasal cannula therapy (HHHFNC) was originally described as a mode of respiratory support in premature neonates and is now increasingly used in the management of acute respiratory failure in older infants and children. Heating and humidification of gas mixtures allow comfortable delivery of flow rates that match or exceed the patient's inspiratory flow rate. Emerging evidence from observational studies suggests that the use of HHHFNC therapy may be associated with reduced work of breathing, improved ventilation efficiency and a decreased need for intubation in children with respiratory insufficiency. There are several proposed mechanisms of action, and the potential for provision of unpredictable positive distending pressure has caused concern. Randomised controlled trial evidence comparing clinical outcomes with those achieved using other forms of respiratory support is, however, awaited. We review the proposed mechanisms of actions, indications, advantages and complications of HHHFNC therapy in children and describe our approach to its use in the paediatric ward environment.

\section{INTRODUCTION}

Administration of supplementary oxygen forms an essential part of the management of hypoxaemic respiratory failure. Nasal cannulae are a wellestablished mode of delivery of oxygen therapy but the amount of oxygen that can be delivered has traditionally been limited by poor tolerance of flow rates $>2 \mathrm{~L} / \mathrm{min}$ in children. The heating (to body temperature) and humidification (to $>99 \%$ relative humidity) of oxygen and air mixtures allow comfortable delivery at flow rates which match or exceed the patient's inspiratory flow rate, thus limiting entrainment of room air. This is known as heated humidified high-flow nasal cannula (HHHFNC) therapy. Commercially available highflow nasal cannula therapy sets are open systems, with leaks at the mouth and nose and can be used with nasal prongs of varying sizes. ${ }^{1}$ In addition to improving oxygenation, HHHFNC therapy may improve the efficiency of ventilation, reduce work of breathing and avoid the need for intubation. ${ }^{2-4}$

The concept of high-flow nasal cannula therapy began in Neonatal Intensive Care Units as an alternative to continuous positive airway pressure (CPAP) in babies with apnoea of prematurity. ${ }^{5}$ HHHFNC therapy is now a common mode of respiratory support in premature neonates; the evidence for its role in this patient group is reviewed elsewhere. ${ }^{6}$ Despite a lack of randomised controlled trial evidence for its effectiveness, HHHFNC therapy is increasingly being used in the management of acute respiratory failure in infants and older children. The proposed mechanisms of actions, indications, advantages and complications of HHHFNC therapy in this setting will be reviewed. We will also outline our approach to the use of HHHFNC therapy in the paediatric ward environment, including potential strategies for escalation and weaning.

\section{MECHANISMS OF ACTION OF HHHFNC THERAPY}

Observational studies have shown improvement in physiological parameters in children receiving HHHFNC therapy. Respiratory distress scores significantly improved as HHHFNC therapy flow rates increased in infants with bronchiolitis and older children requiring oxygen therapy. ${ }^{7}$ In another cohort of paediatric patients (median age 6.5 months) receiving HHHFNC therapy on a Paediatric Intensive Care Unit (PICU), measured work of breathing significantly decreased as HHHFNC therapy increased from 2 to $8 \mathrm{~L} / \mathrm{min}^{9}{ }^{9}$ A further study in infants with moderately severe bronchiolitis showed HHHFNC therapy to be associated with a rapid decrease in median end-tidal carbon dioxide and respiratory rate during the first $3 \mathrm{~h}$ of treatment. These parameters then remained steady during the following $48 \mathrm{~h}$ of therapy. ${ }^{10}$

It is proposed that HHHFNC therapy reduces work of breathing and improves efficiency of ventilation through several mechanisms: ${ }^{2}$

1. washout of nasopharyngeal deadspace leading to improved alveolar ventilation

2. reduction in the inspiratory resistance associated with the nasopharynx

3. improvement in conductance and pulmonary compliance by supplying adequately warmed and humidified gas

4. reduction in metabolic work associated with gas conditioning

5. may provide positive distending pressure for lung recruitment.

There is evidence that HHHFNC therapy provides positive distending pressure and concern that this may be unpredictable. Small studies in preterm infants have demonstrated linear relationships between flow rate and distending pressure but reported conflicting data about the significance of mouth closure. ${ }^{11}{ }^{12}$ The degree of leak at the nares-prong interface is felt to be important, and manufacturers of HHHFNC therapy systems advise using prongs that are no greater than half the diameter of the nares. ${ }^{1}$ HHHFNC therapy at rates of $2 \mathrm{~L} / \mathrm{kg} / \mathrm{min}$ in infants with viral bronchiolitis, using a nasal prong approximately half the diameter of the nostril, generated mean pharyngeal pressures of $\geq 4 \mathrm{cmH}_{2} \mathrm{O}^{7}$ Flow rates of $\geq 6 \mathrm{~L} / \mathrm{min}$ were 
associated with positive pharyngeal pressures throughout the respiratory cycle. Another study in infants with bronchiolitis found a linear association between increasing HHHFNC therapy flow rates and nasopharyngeal pressure, with a reduction in the rate of increase in pressure with flow rates $>6 \mathrm{~L} / \mathrm{min}^{13}$ On average, nasopharyngeal pressure increased by $0.45 \mathrm{cmH}_{2} \mathrm{O}$ for every $1 \mathrm{~L} / \mathrm{min}$ increase in flow rate. Pressures were significantly higher in mouth-closed states. A study in older children (median age 2.8 years) found an average positive end expiratory pressure of $4 \pm 1.99 \mathrm{cmH}_{2} \mathrm{O}$ when flow rates of 8-10 times minute ventilation (approximately $8-10 \mathrm{~L} / \mathrm{min}$ in infants and $20-30 \mathrm{~L} / \mathrm{min}$ in children) were delivered. ${ }^{8}$ The pressure generated decreased as weight increased.

\section{ROLE OF HHHFNC THERAPY IN BRONCHIOLITIS}

Bronchiolitis is the most common cause of lower respiratory tract infection during the first year of life; a recent study involving National Health Service hospitals in the UK found an admission of rate of 24.2 per 1000 infants. ${ }^{14}$ Avoiding the need for admission to an intensive care unit and, in particular, the need for invasive respiratory support with its associated potential for respiratory, cardiovascular and neurological complications, is a key management goal. The role of HHHFNC therapy in infants with bronchiolitis is, therefore, of particular interest.

Small retrospective studies of HHHFNC therapy use in infants with bronchiolitis suggest that it is a safe mode of respiratory support which may provide an alternative to nasal CPAP. In one study, 45 infants with moderately severe bronchiolitis who would have traditionally been transferred to a Paediatric High Dependency Unit for nasal CPAP received HHHFNC therapy on a general paediatric ward; 11 required escalation of respiratory support but HHHFNC therapy reduced the number of infants requiring transfer for $\mathrm{CPAP}^{15}$ In another study, data relating to 34 infants admitted to a PICU with bronchiolitis during two consecutive winters were retrospectively reviewed. ${ }^{16}$ Nasal CPAP was used as first-line noninvasive respiratory support during the first winter and was replaced by HHHFNC (initial flow rate $1 \mathrm{~L} / \mathrm{kg} / \mathrm{min}$, up to a maximum of $8 \mathrm{~L} / \mathrm{min}$ ) during the second winter. There was no statistically significant difference in physiological parameters (heart rate, respiratory rate, fraction of inspired oxygen $\left(\mathrm{F}_{\mathrm{i}} \mathrm{O}_{2}\right)$ or partial pressure of carbon dioxide $\left(\mathrm{pCO}_{2}\right)$ ) or length of PICU stay between the two groups. Reductions in rates of intubation in infants with bronchiolitis have also been reported following introduction of HHHFNC therapy. A $68 \%$ reduction in intubation rate was observed on an American PICU following institution of HHHFNC therapy for this group of patients, while an Australian group reported a reduction in intubation rate from $37 \%$ to $7 \%$ in infants admitted to their PICU with viral bronchiolitis during the 5 -year period following introduction of HHHFNC therapy. ${ }^{3} 4$

There are limited prospective data relating to HHHFNC therapy in bronchiolitis. In a small pilot study, 19 infants with moderately severe bronchiolitis were randomised to either headbox oxygen or HHHFNC therapy for at least $24 \mathrm{~h}$ (started at $4 \mathrm{~L} / \mathrm{min}$ and increased to $8 \mathrm{~L} / \mathrm{min}$ if tolerated). ${ }^{17}$ Median oxygen saturation was higher in infants receiving HHHFNC therapy at 8 and $12 \mathrm{~h}$ after randomisation but duration of oxygen therapy, time to feed and total length of stay were similar between the two groups. No infant required further respiratory support. This was the only study to be included in a recent Cochrane review of the role of HHHFNC therapy in bronchiolitis which concluded that there was insufficient evidence for its effectiveness. ${ }^{18}$ Several ongoing randomised controlled trials comparing HHHFNC therapy with standard oxygen therapy were identified and will be included in future updates. An Australian study comparing prospectively identified infants with bronchiolitis who received HHHFNC therapy with retrospectively identified controls (who received low-flow nasal oxygen therapy) found that the infants receiving HHHFNC therapy were four times less likely to require PICU admission (OR 4.09, $\mathrm{p}=0.043) .{ }^{19}$ The authors propose using their data to guide development of a randomised controlled trial of HHHFNC therapy in bronchiolitis using PICU admission as the primary outcome.

\section{ROLE OF HHHFNC THERAPY IN RESPIRATORY DISTRESS DUE TO CONDITIONS OTHER THAN BRONCHIOLITIS}

Outside of its role in infants with bronchiolitis, there is relatively limited evidence for HHHFNC therapy in children. A Cochrane review of the role of HHHFNC therapy as respiratory support in children (excluding those with bronchiolitis) did not identify any randomised controlled trials comparing HHHFNC therapy with other forms of non-invasive support. ${ }^{20}$ The successful use of HHHFNC therapy has been described in children with respiratory pathology other than bronchiolitis, including viral-induced wheeze, obstructive sleep apnoea and post-extubation stridor. ${ }^{21-23} \mathrm{~A}$ single-centre retrospective study of children with acute respiratory insufficiency (including asthma, pneumonia, bronchiolitis and croup) requiring PICU admission found introduction of HHHFNC therapy in the emergency department to be associated with a reduction in intubation rate from $16 \%$ to $8 \% .^{24}$

There are some limited data relating to the potential use of HHHFNC therapy in paediatric cardiac patients. A recent single-centre, randomised trial compared HHHFNC therapy with low-flow oxygen therapy after extubation in postoperative cardiac patients under the age of 18 months. ${ }^{25}$ The partial pressure of oxygen $/ \mathrm{F}_{\mathrm{i}} \mathrm{O}_{2}$ was similar between the two groups at baseline but much higher in the HHHFNC therapy group at all time points during the 48-hour study period. There was no difference in $\mathrm{pCO}_{2}$ values at any time point. Seven of $46(15 \%)$ patients in the low-flow oxygen group required non-invasive respiratory support compared with none in the HHHFNC therapy group. Two patients in each group required emergency reintubation and ventilation. The successful use of HHHFNC therapy has also been described in patients with cardiomyopathy and acute pulmonary oedema. ${ }^{21} 26$

\section{ROLE OF HHHFNC THERAPY IN TRANSPORT OF CRITICALLY ILL CHILDREN}

An Australian centre has reported its experience of HHHFNC therapy use during the interhospital transport of critically ill children under the age of 2 years. ${ }^{27}$ A total of 793 children were studied over an 8-year period: 331 children were transported during the 4 years prior to the introduction of HHHFNC therapy and 462 children were transported afterwards. During the second 4-year period, 33\% of children were supported with HHHFNC therapy and there was a significant decrease in the number of children requiring retrieval on invasive ventilation (49\% pre-HHHFNC therapy vs $35 \%$ post-HHHFNC therapy, $\mathrm{p}=0.001)$. Rates of retrieval on non-invasive ventilation also reduced from $7 \%$ to $2 \%$. There was no significant change in the number of retrieved children requiring intubation for respiratory reasons during the first $24 \mathrm{~h}$ after PICU admission. 


\section{ADVANTAGES OF HHHFNC THERAPY}

In contrast to low-flow oxygen therapy, HHHFNC therapy provides constant, measurable and adjustable oxygen concentrations. The use of nasal cannulae rather than a mask allows the patient to communicate and drink more easily, if their clinical condition allows. Children who received oxygen via nasal cannula or facemask were found to have a significant improvement in COMFORT scores (a validated measure of distress in children in the intensive care setting) within 60-90 min of switching to HHHFNC therapy. ${ }^{8}$ The COMFORT score continued to improve over the next 8-12 h.

HHHFNC therapy has been proposed as an alternative to CPAP in some clinical situations and may have advantages. The need to maintain an adequate facial seal in children receiving CPAP can make delivery challenging but this is not required with HHHFNC therapy. The tubing associated with CPAP is more cumbersome than that of HHHFNC therapy. A small randomised cross-over trial of HHHFNC therapy and CPAP in premature infants found no differences in objective measurement of patient comfort or ambient noise. ${ }^{28}$ However, parents assessed HHHFNC therapy as significantly increasing child satisfaction, parental contact and interaction, and parental ability to take part in care. A randomised controlled trial comparing HHHFNC therapy with CPAP in premature neonates after extubation found a significantly lower incidence of nasal trauma in babies who received HHHFNC therapy $(39.5 \%$ vs $54.3 \%, p=0.01){ }^{29}$ A similar trend was observed during an observational study comparing HHHFNC therapy with nasopharyngeal-prong CPAP in children admitted to a PICU. ${ }^{30}$ One of 72 HHHFNC therapy patients experienced mucosal injury compared with six of the 37 CPAP patients. In addition, two patients receiving CPAP developed pneumothoraces. The same study found a trend towards less use of sedation with HHHFNC therapy. Chloral hydrate was used in $38 \%$ of HHHFNC therapy episodes versus $60 \%$ of CPAP episodes. Five per cent of children receiving HHHFNC therapy required more than one sedative agent versus $11 \%$ of children receiving CPAP $(\mathrm{p}=0.17)$. These results, perhaps, need cautious interpretation as nasopharyngeal-prong CPAP is not widely used and the sedation usage seems relatively high.

\section{COMPLICATIONS OF HHHFNC THERAPY}

\section{Abdominal distension}

Two small patient studies have reported abdominal distension in children receiving HHHFNC therapy. ${ }^{25}$ This may limit its application in certain settings, for example, in children with intra-abdominal pathology.

\section{Infection}

An outbreak of Ralstonia spp infection in the USA in 2005 was microbiologically and epidemiologically linked to the use of the Vapotherm 2000i HHHFNC therapy system. ${ }^{31}$ This device was recalled and modifications were made to the manufacturing process prior to reintroduction. No further infectious complications have been reported.

\section{Air leaks}

A case series of three children who developed air leaks (pneumothoraces in two children and pneumomediastinum in the third child) while receiving HHHFNC therapy has been recently described. The authors cite the potential for an unpredictable rise in positive airways pressure as a possible contributory factor. ${ }^{32}$ A further case report describes subcutaneous scalp emphysema, pneumo-orbitis and pneumocephalus, but no pneumothorax or pneumomediastinum, in a premature infant receiving HHHFNC therapy. ${ }^{33}$

\section{DEVELOPMENT OF LOCAL GUIDANCE}

HHHFNC therapy has been increasingly used in the management of respiratory distress on the paediatric wards in our hospital. ${ }^{17}$ Recently published guidance on high-dependency care for children suggests that HHHFNC therapy is an intervention that should be available to all children admitted to inpatient paediatric facilities. ${ }^{34}$ However, there is little evidence to guide practice in this environment. A retrospective review of 498 children presenting to two tertiary emergency departments with respiratory distress found higher venous $\mathrm{pCO}_{2}(>50 \mathrm{~mm} \mathrm{Hg})$, lower venous $\mathrm{pH}(<7.3)$ and higher respiratory rate at triage (>90th percentile for age) to be independently associated with the need for intubation within $24 \mathrm{~h}$ of commencing HHHFNC therapy. ${ }^{35}$ A final diagnosis of bronchiolitis was found to be protective against the need for invasive ventilation. Another retrospective review of infants with bronchiolitis, who failed treatment with HHHFNC therapy and required mechanical ventilation, found that higher pretherapy $\mathrm{pCO}_{2}$ and failure of reduction in respiratory rate to be the strongest predictors of the need for intubation. ${ }^{36}$ Other studies have shown the absence of normalisation of heart rate and respiratory rate, and failure of $\mathrm{F}_{\mathrm{i}} \mathrm{O}_{2}$ to fall to $<0.5$, during the first $1-2 \mathrm{~h}$ of treatment to be associated with failure of HHHFNC therapy. ${ }^{19} 30$

Ensuring that an appropriate form of respiratory support is delivered in a safe environment and that children requiring escalation of support are identified early, forms the basis of our recently developed local guidance on the use of HHHFNC therapy. To maintain consistency with the observations recorded by the nursing staff in our hospital, criteria for commencing HHHFNC therapy, and strategies for escalation and weaning, are based on the respiratory component of our local Paediatric Early Warning (PEW) Score. This comprises respiratory rate (varies with age), degree of respiratory distress and oxygen saturation. If the respiratory component of the PEW score reaches a trigger level, the child is reviewed to determine whether increased respiratory support is required and, if so, what form of support is appropriate (figure 1). Initial flow rates are dependent on age and are increased if the respiratory component of the PEW Score remains at or above the initial trigger level (figure 2). $\mathrm{F}_{\mathrm{i}} \mathrm{O}_{2}$ is set at 0.4 initially and increased to 0.5 if oxygen saturations are $<92 \%$. Alternative settings may be more appropriate in some cases, for example, children with chronic hypoxaemia or congenital heart disease. Children who have reached maximal escalation thresholds are considered to have 'failed' a trial of HHHFNC therapy; they require urgent referral to the Paediatric Critical Care (Transport) team and an increased level of respiratory support. Another approach to the initiation of HHHFNC involves varying initial flow rates according to weight (eg, $2 \mathrm{~L} / \mathrm{min}$ flow per $\mathrm{kg}$ ) although this would seem to be somewhat problematic outside of infancy as very high flow rates are likely to be needed for relatively small children. From anecdotal experience, the use of very high flow rates outside critical care environments may lead to children with very significant respiratory distress not being appropriately identified. In certain cases, children have had to convert directly from HHHFNC therapy to high pressure invasive ventilation, including high-frequency oscillatory ventilation, as a clinical emergency and in a less than controlled fashion.

Our local guidelines suggest that weaning of HHHFNC therapy should be commenced if the respiratory component of the local PEW Score falls below the initial trigger level. Our 
Figure 1 Approach and response to a child with increasing respiratory difficulty in a non-critical care environment (in-patient ward, assessment unit or emergency department). HHHFNC, heated humidified high-flow nasal cannula therapy.

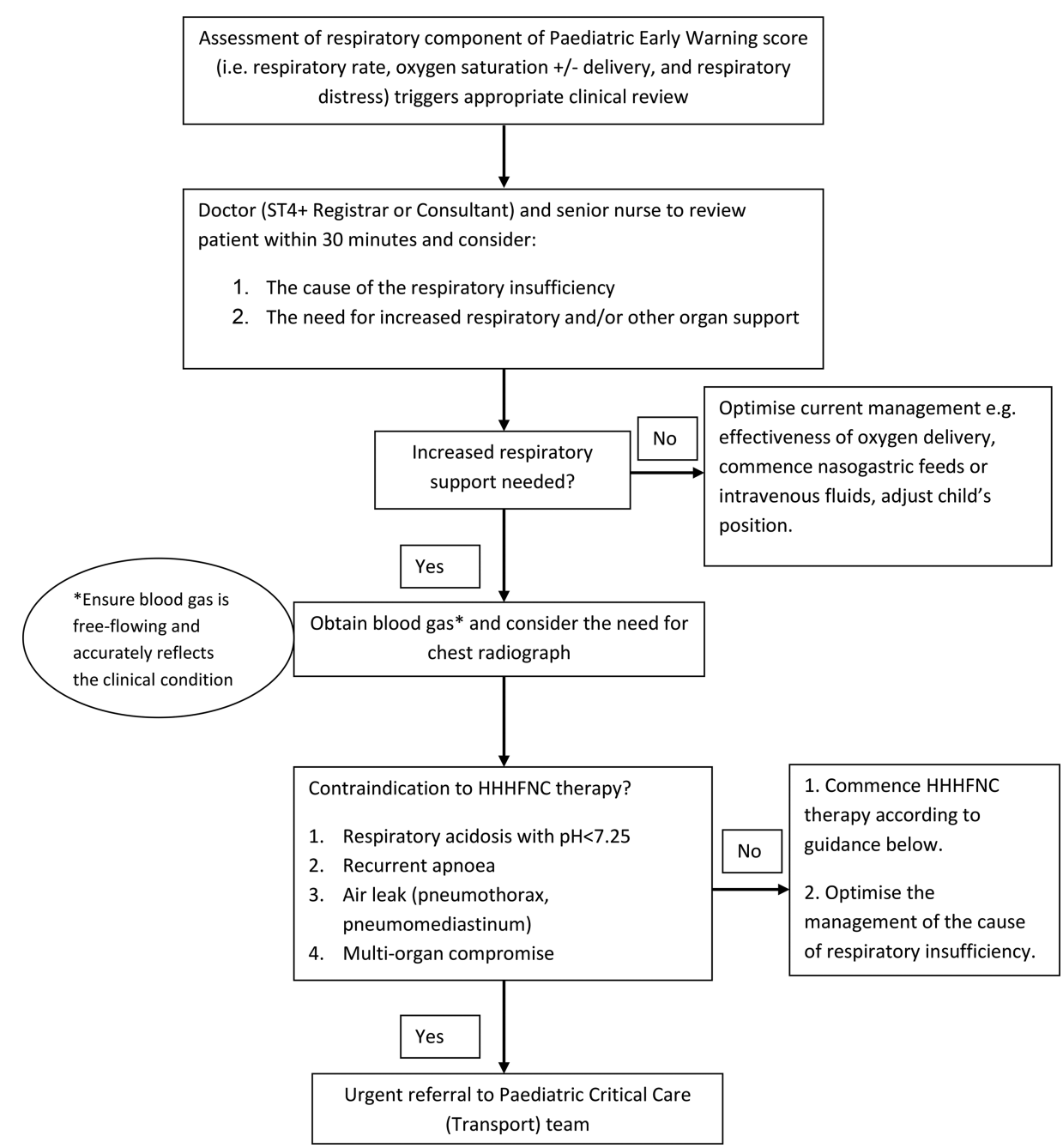

\begin{tabular}{|c|c|c|c|c|}
\hline & $\begin{array}{c}\text { Neonate } \\
\text { (Up to } 1 \text { month) }\end{array}$ & $\begin{array}{c}\text { Infant } \\
\text { (1 month-12 months) }\end{array}$ & $\begin{array}{l}\text { Pre-school } \\
\text { (1-4 years) }\end{array}$ & $\begin{array}{c}\text { School-aged } \\
\text { (5 years and over) }\end{array}$ \\
\hline $\begin{array}{l}\text { Initial } \\
\text { settings }\end{array}$ & $6 \mathrm{~L} / \mathrm{min}$ and $\mathrm{F}_{\mathrm{i}} \mathrm{O}_{2} 40 \%$. & $8 \mathrm{~L} / \mathrm{min}$ and $\mathrm{F}_{1} \mathrm{O}_{2} 40 \%$. & $10 \mathrm{~L} / \mathrm{min}$ and $\mathrm{F}_{\mathrm{i}} \mathrm{O}_{2} 40 \%$. & $12 \mathrm{~L} / \mathrm{min}$ and $\mathrm{F}_{\mathrm{i}} \mathrm{O}_{2} 40 \%$. \\
\hline $\begin{array}{l}\text { First } \\
\text { escalation of } \\
\text { therapy* }\end{array}$ & Increase flow rate to $8 \mathrm{~L} / \mathrm{min}$. & Increase flow rate to $10 \mathrm{~L} / \mathrm{min}$. & Increase flow rate to $12 \mathrm{~L} / \mathrm{min}$. & Increase flow rate to $16 \mathrm{~L} / \mathrm{min}$. \\
\hline $\begin{array}{l}\text { Second } \\
\text { escalation of } \\
\text { therapy* }\end{array}$ & $\begin{array}{l}\text { Increase } \mathrm{F}_{\mathrm{i}} \mathrm{O}_{2} \text { to } 50 \% \text { if oxygen } \\
\text { saturations are less than } 92 \% \text {. }\end{array}$ & $\begin{array}{l}\text { Increase } \mathrm{F}_{\mathrm{i}} \mathrm{O}_{2} \text { to } 50 \% \text { if oxygen } \\
\text { saturations are less than } 92 \% \text {. }\end{array}$ & $\begin{array}{l}\text { Increase } \mathrm{F}_{\mathrm{i}} \mathrm{O}_{2} \text { to } 50 \% \text { if oxygen } \\
\text { saturations are less than } 92 \% \text {. }\end{array}$ & $\begin{array}{l}\text { Increase } \mathrm{F}_{\mathrm{i}} \mathrm{O}_{2} \text { to } 50 \% \text { if oxygen } \\
\text { saturations are less than } 92 \% \text {. }\end{array}$ \\
\hline $\begin{array}{l}\text { Third } \\
\text { escalation of } \\
\text { therapy* }\end{array}$ & $\begin{array}{l}\text { Increase } \mathrm{F}_{\mathrm{i}} \mathrm{O}_{2} \text { to maintain } \\
\text { oxygen saturations at least } \\
92 \% \text { and urgent referral to } \\
\text { Paediatric Critical Care } \\
\text { (Transport) team. }\end{array}$ & $\begin{array}{l}\text { Increase } \mathrm{F}_{\mathrm{i}} \mathrm{O}_{2} \text { to maintain } \\
\text { oxygen saturations at least } \\
92 \% \text { and urgent referral to } \\
\text { Paediatric Critical Care } \\
\text { (Transport) team. }\end{array}$ & Increase flow rate to $15 \mathrm{~L} / \mathrm{min}$. & Increase flow rate to $20 \mathrm{~L} / \mathrm{min}$. \\
\hline $\begin{array}{l}\text { Fourth } \\
\text { escalation of } \\
\text { therapy* }\end{array}$ & N/A & N/A & $\begin{array}{l}\text { Increase } \mathrm{F}_{\mathrm{i}} \mathrm{O}_{2} \text { to maintain } \\
\text { oxygen saturations at least } \\
92 \% \text { and urgent referral to } \\
\text { Paediatric Critical Care } \\
\text { (Transport) team. }\end{array}$ & $\begin{array}{l}\text { Increase } \mathrm{F}_{i} \mathrm{O}_{2} \text { to maintain } \\
\text { oxygen saturations at least } \\
92 \% \text { and urgent referral to } \\
\text { Paediatric Critical Care } \\
\text { (Transport) team. }\end{array}$ \\
\hline
\end{tabular}

$\mathrm{F}_{\mathrm{i}} \mathrm{O}_{2}=$ Fraction of inspired oxygen

*HHHFNC therapy should be escalated if:

1. Oxygen saturations are less than $92 \%$ and/or

2. The respiratory component of the PEW Score (respiratory rate, oxygen saturation and degree of respiratory distress) increases above initiation trigger point

Figure 2 Approach to initiation and escalation of heated humidified high-flow nasal cannula (HHHFNC) therapy for children of different ages. PEW, Paediatric Early Warning. 
approach is to initially wean the $\mathrm{F}_{\mathrm{i}} \mathrm{O}_{2}$ to 0.4 before reducing flow rates by $0.5 \mathrm{~L} / \mathrm{min} / \mathrm{h}$ for neonates and $1 \mathrm{~L} / \mathrm{min} / \mathrm{h}$ for all other children, as long as the respiratory component of the local PEW Score remains below the initial trigger level. If at any point of the weaning process the respiratory component of the local PEW Score reaches or rises above the initial trigger level, the flow rate or $\mathrm{F}_{\mathrm{i}} \mathrm{O}_{2}$ is increased back to the previous higher level. HHHFNC therapy is discontinued once the flow rate is below the initial starting flow rate for the age of child and the oxygen saturations are maintained above $92 \%$ with a $\mathrm{F}_{\mathrm{i}} \mathrm{O}_{2}$ of 0.4 . Some centres use other approaches to weaning, such as gradually reducing $\mathrm{F}_{\mathrm{i}} \mathrm{O}_{2}$ to 0.21 (room air) while maintaining appropriate oxygen saturations. HHHFNC therapy is discontinued when the child remains well saturated in air. Unfortunately, at present, there is no evidence to suggest that any particular approach to weaning HHHFNC is either more effective or efficient.

\section{SUMMARY}

Observational studies suggest that HHHFNC therapy may reduce work of breathing and improve the efficiency of ventilation in children, possibly with clinically significant outcomes such as avoidance of the need for CPAP and a reduced requirement for invasive ventilation. HHHFNC therapy may have advantages over other forms of oxygen delivery and noninvasive respiratory support, such as improved comfort and reduced mucosal injury. Several randomised controlled trials are underway to compare outcomes with HHHFNC therapy with those achieved using other forms of respiratory support. Pending publication of further evidence, we suggest that children receiving HHHFNC therapy are managed in appropriate settings where the need for escalation to other forms of respiratory support is identified in a timely manner.

Acknowledgements The authors wish to thank Dr Caroline Haines for her contribution to the development of local guidance on the use of heated humidified high-flow nasal cannula therapy.

Contributors TNH had the original idea to write this review. FAH wrote the first draft and this was edited equally by TNH and PJD.

Competing interests None.

Provenance and peer review Commissioned; externally peer reviewed.

\section{REFERENCES}

1 Miller T. High flow therapy and humidification: a summary of mechanisms of action, technology and research. Vapotherm, Inc., 2008.

2 Dysart K, Miller TL, Wolfson MR, et al. Research in high flow therapy: mechanisms of action. Respir Med 2009;103:1400-5.

3 McKiernan C, Chua LC, Visintainer PF, et al. High flow nasal cannulae therapy in infants with bronchiolitis. J Pediatr 2010;156:634-8.

4 Schibler A, Pham TM, Dunster KR, et al. Reduced intubation rates for infants after introduction of high-flow nasal prong oxygen delivery. Intensive Care Med 2011;37:847-52.

5 Sreenan C, Lemke RP, Hudson-Mason A, et al. High-flow nasal cannulae in the management of apnea of prematurity: a comparison with conventional nasal continuous positive airway pressure. Pediatrics 2001;107:1081-3.

6 DeMauro SB, Millar D, Kirpalani H. Noninvasive respiratory support for neonates. Curr Opin Pediatr 2014;26:157-62.

7 Milési C, Baleine J, Matecki S, et al. Is treatment with a high flow nasal cannula effective in acute viral bronchiolitis? A physiologic study. Intensive Care Med 2013;39:1088-94.

8 Spentzas $T$, Minarik $M$, Patters $A B$, et al. Children with respiratory distress treated with high-flow nasal cannula. J Intensive Care Med 2009;24:323-8.

9 Rubin S, Ghuman A, Deakers T, et al. Effort of breathing in children receiving high-flow nasal cannula. Pediatr Crit Care Med 2014;15:1-6.
10 Bressan S, Balzani M, Krauss B, et al. High-flow nasal cannula oxygen for bronchiolitis in a pediatric ward: a pilot study. Eur J Pediatr 2013;172:1649-56.

11 Wilkinson DJ, Andersen CC, Smith K, et al. Pharyngeal pressure with high-flow nasal cannulae in premature infants. J Perinatol 2008:28:42-7.

12 Kubicka ZJ, Limauro J, Darnall RA. Heated, humidified high-flow nasal cannula therapy: yet another way to deliver continuous positive airway pressure? Pediatrics 2008; 121:82-8

13 Arora B, Mahajan P, Zidan MA, et al. Nasopharyngeal airway pressures in bronchiolitis patients treated with high-flow nasal cannula oxygen therapy. Pediatr Emerg Care 2012;28:1179-84.

14 Murray J, Bottle A, Sharland M, et al. Risk factors for hospital admission with RSV bronchiolitis in England: a population-based birth cohort study. PLOS ONE 2014;9: e89186.

15 Kallappa C, Hufton M, Millen G, et al. Use of high flow nasal cannula oxygen (HFNCO) in infants with bronchiolitis on a paediatric ward: a 3-year experience. Arch Dis Child 2014;99:790-1.

16 Metge P, Grimaldi C, Hassid S, et al. Comparison of a high-flow humidified nasal cannula to nasal continuous positive airway pressure in children with acute bronchiolitis: experience in a pediatric intensive care unit. Eur J Pediatr 2014;173:953-8

17 Hilliard TN, Archer N, Hole L, et al. Pilot study of vapotherm oxygen delivery in moderately severe bronchiolitis. Arch Dis Child 2012;97:182-3.

18 Beggs S, Wong ZH, Kaul S, et al. High-flow nasal cannula therapy for infants with bronchiolitis. Cochrane Database Syst Rev 2014;(1):CD009609.

19 Mayfield S, Bogossian F, O'Malley L, et al. High-flow nasal cannula oxygen therapy for infants with bronchiolitis: pilot study. J Paediatr Child Health 2014;50:373-8

20 Mayfield S, Jauncey-Cooke J, Hough JL, et al. High-flow nasal cannula therapy for respiratory support in children. Cochrane Database Syst Rev 2014;(3):CD009850.

21 Mayfield S, Jauncey-Cooke J, Bogossian F. A case series of paediatric high flow nasal cannula therapy. Aust Crit Care 2013;26:189-2.

22 McGinley B, Halbower A, Schwartz AR, et al. Effect of a high-flow open nasal cannula system on obstructive sleep apnea in children. Pediatrics 2009;124:179-88.

23 Byerly FL, Haithcock JA, Buchanan IB, et al. Use of high flow nasal cannula on a pediatric burn patient with inhalation injury and post-extubation stridor. Burns 2006:32:121-5.

24 Wing R, James C, Maranda LS, et al. Use of high-flow nasal cannula support in the emergency department reduces the need for intubation in pediatric acute respiratory insufficiency. Pediatr Emerg Care 2012;28:1117-23.

25 Testa $G$, lodice F, Ricci Z, et al. Comparative evaluation of high-flow nasal cannula and conventional oxygen therapy in paediatric cardiac surgical patients: a randomized controlled trial. Interact Cardiovasc Thorac Surg 2014;19:456-1.

26 Kumar J, Hegde R, Maheshwari S, et al. Flash pulmonary edema in a post arterial switch operation-High flow oxygen as a treatment modality. Ann Pediatr Cardiol 2009;2:175-6.

27 Schlapbach LJ, Schaefer J, Brady AM, et al. High-flow nasal cannula (HFNC) support in interhospital transport of critically ill children. Intensive Care Med 2014;40:592-9.

28 Klingenberg C, Pettersen M, Hansen EA, et al. Patient comfort during treatment with heated humidified high flow nasal cannulae versus nasal continuous positive airway pressure: a randomised cross-over trial. Arch Dis Child Fetal Neonatal Ed 2014;99:F134-7.

29 Manley BJ, Owen LS, Doyle LW, et al. High-flow nasal cannulae in very preterm infants after extubation. N Engl J Med 2013;369:1425-33.

30 ten Brink F, Duke T, Evans J. High-flow nasal prong oxygen therapy or nasopharyngeal continuous positive airway pressure for children with moderate-to-severe respiratory distress? Pediatr Crit Care Med 2013;14:e326-31.

31 Jhung MA, Sunenshine RH, Noble-Wang J, et al. A national outbreak of Ralstonia mannitolilytica associated with use of a contaminated oxygen-delivery device among pediatric patients. Pediatrics 2007;119:1061-8.

32 Hegde $S$, Prodhan P. Serious air leak syndrome complicating high-flow nasal cannula therapy: a report of 3 cases. Pediatrics 2013;131:e939-44.

33 Jasin LR, Kern S, Thompson S, et al. Subcutaneous scalp emphysema, pneumo-orbitis and pneumocephalus in a neonate on high humidity high flow nasal cannula. J Perinatol 2008;28:779-81.

34 High Dependency Care for Children-Time to Move On. London: Royal College of Paediatrics and Child Health, 2014.

35 Kelly GS, Simon HK, Sturm JJ. High-flow nasal cannula use in children with respiratory distress in the emergency department: predicting the need for subsequent intubation. Pediatr Emerg Care 2013;29:888-92.

36 Abboud PA, Roth PJ, Skiles CL, et al. Predictors of failure in infants with viral bronchiolitis treated with high-flow, high-humidity nasal cannula therapy. Pediatr Crit Care Med 2012;13:e343-9. 